Academic Platform Journal of Engineering and Science

journal homepage: $\underline{\text { http://apjes.com/ }}$

\title{
Fiziksel Performans Etkisinde Mental Aktivitenin Elektrofizyolojik Bulgularının Değerlendirilmesi
}

\author{
*11Dilek Göksel Duru, ${ }^{1}$ Elif Işsıçı Koca \\ ${ }^{1}$ Yazar İstanbul Arel Üniversitesi, Mühendislik-Mimarlık Fakültesi, Biyomedikal Mühendisliği Bölümü, İstanbul/Türkiye, \\ *dilekgokselduru@arel.edu.tr, iD \\ elifisikci@arel.edu.tr,
}

Bu çalışmada, zihinsel işyükü paradigmasının yorgunluk ile ilintisine yönelik elektrofizyolojik ölçüm sonuçları iki farklı grup üzerinden incelenmiştir. Ayrık grup olarak, sporcular ve sedanterler ele alınmış olup, bu grupların beyin dinlenim durumu bulguları ile mental performans esnasındaki gerçek zamanlı elektrofizyolojik ölçümleri karşılaştırılmış ve bu bulgulardaki değişimler incelenmiştir. Mental aritmetik işlem ile zihinsel işyükü yaratılarak, kontrollü bir fiziksel performans öncesinde ve sonrasında VO2max değeri ve eşzamanlı EEG, PPG, EDA ve EKG ölçümleri gerçekleştirilmiştir. Farklı gruplara ait dinlenim durumu mental performansları ve fiziksel aktivite sonrasında oluşan mental işyükü arasındaki kalp atım hızı değişkenliği, oksijen tüketimi miktarı tartışılmıştır. Bulgularda, zihinsel işyükü süresince ölçümlenen EEG'de alfa frekansında baskılanma ile elektriksel deri direncinde artış görülmüştür. Ölçümlenen kalp atım hızı verileri parametrik olmayan istatistik test ile incelenmiş ve $0.15-0.4 \mathrm{~Hz}$ arası aralığındaki dinlenim durumu için istatistiksel anlamlı bulgular elde edilmiştir $(\mathrm{p}<0.05)$. Sonuç olarak, zihinsel aritmetik işyükünün kontrollü yorgunluk sağlanmış ölçümlerde, elektriksel beyin aktivitesinde alfa tutulumuna yol açtığı gözlemlenmiş ve ayrıca alfa değişiminin sporcu grup içinde daha az olduğu saptanmıştır. PPG sinyalleri değerlendirildiğinde, sporculardaki değişimin daha az olduğu, ayrıca sporcu gönüllülere ait PPG sinyallerindeki değişimin varyasyon sergileyebileceği gözlemlenmiştir. Raporlanan öncül bulgular doğrultusunda, fiziksel yorgunluk şartlarında incelenen iki grup için, sporcuların odaklanmalarının daha başarılı olduğu ve zihinsel işyükünden daha az etkilendikleri öngörülebilmektedir.

Anahtar Kelimeler: Alfa Baskılanması, Aerobik Kapasite, Mental İşyükü, Nöral Yetkinlik

\section{Assessment of Electrophysiological Findings during Mental Workload in the Effect of Physical Performance}

\author{
*1Dilek Göksel Duru, ${ }^{1}$ Elif Işıkçı Koca \\ ${ }^{1}$ Istanbul Arel University, Faculty of Engineering and Architecture, Department of Biomedical Engineering, Istanbul/Turkey, \\ *dilekgokselduru@arel.edu.tr
}

\begin{abstract}
The present study examines the findings of electrophysiological measurements of two groups related to the correlation of the mental workload paradigm to tiredness. Athletes and non-athletes (sedentary) are investigated as discrete groups. The aim here is to investigate the findings of the resting state brain network and the electrophysiologic measurements during mental performance of these groups and the changes and variations related to these findings. Mental workload is achieved via mental arithmetic backward counting, while aerobic capacity VO2max, EEG, PPG, EDA and ECG are being measured simultaneously, before and after physical performance. The study also discusses the oxygen consumption rate and the heart rate variability (HRV) between the resting state mental performance and the mental workload occurred after physical activity of varying groups. Thus, findings on the investigation of the effects of physical tiredness on the mental workload of the subjects from two different groups, can be summarized as follows: Increase in the alpha suppression and electrodermal activity during mental work performance has been detected. The heart rate variability data has been investigated with nonparametric statistical test. Statistical test results of
\end{abstract}


resting state for eye closed paradigm for frequency range of $0.15-0.4 \mathrm{~Hz}$ are determined as statistically significant ( $\mathrm{p}<0.05$ ). Alpha frequency suppression is detected as a result for brain electrical activity analysis which are in agreement with literature. The EEG alpha activity detected while mental performance reflects more suppression than the eyes closed resting state alpha activity. To conclude, EEG alpha suppression is caused by mental arithmetic workload in volunteers with controlled physical performance, and the alpha suppression within sportsmen group is less, where the suppression of alpha activity obtained in sportsmen EEG is more explicit than in sedentary. Assessing the PPG signals results less variation in sportsmen. Results specify that PPG signals of sportsmen group represent less variances than PPG data of sedentary group. Also another finding specifies, that PPG signals within group may vary like in sportsmen group. According to these preliminary results, it can be predicted that the athlete group is less affected by mental workload despite being more focused and physically tired.

Keywords: Aerobic capacity, Mental workload, Neural efficiency, Alpha supression

\section{GíRiș}

Zihinsel işyükü (mental efor), bir görev gerçekleştirirken bireylerin performansı üzerinde doğrudan etkisi olması nedeni ile önemlidir [1]. Zihinsel işyükü, mental harcanan enerji olarak düşünülebileceği gibi, hafıza eforu, karar verme veya uyanıklık (alertness) durumu olarak düşünülebilen, bireyin eforunu, farkındalığını ve ilgi seviyesini sergileyen bir göstergedir. Karar verme mekanizmasının yanı sıra zihinsel işyükü paradigması ile bireylerin bir operasyon esnasında mental durumlarının değerlendirilmesi ve yeteneklerinin (iletişim becerisi, yöntemlerin uygulanma şekli gibi) iyileştirilmesi mümkün olabilecektir.

Dikkate ayrılan kaynakların zaman içinde verimli bir şekilde kullanılması karar verme mekanizması ve performans (başarı kriteri) açısından oldukça önem taşımaktadır. Zihinsel faaliyet gerektiren görevlerde kişilerin performansları farklılık göstermekte ve karar verme mekanizmasını etkilemektedir. Nöral yetkinlik (neural efficacy) hipotezinde, bir konuda uzmanlık derecesine ulaşmış kişilerin, sedanter kontrollerle karşılaştırıldığında bilişsel testlerde daha düşük beyin aktivitesi gösterdikleri belirtilmektedir [2,3]. Burada kastedilen görece düşük beyin aktivitesinin daha yeterli ve yetkin anlamında olduğudur. Az enerji ve düşük beyin aktivitesi ile aynı bilişsel işlevin yerine getirilmesi kastedilmektedir. Dolayısıyla konusunda eğitimli bireylerin öğrenme ile beyin aktivitelerini efektif kullandığ ve profesyoneller ile amatörler arasında karar verme mekanizmasının farklılığı söylenebilmektedir [4].

EEG literatüründe mental işyükü değerlendirmesi için s1klıkla beyin elektriksel aktivitelerinin alfa $(8-13 \mathrm{~Hz})$ ve teta $(4-8 \mathrm{~Hz})$ frekans bantları, özellikle Pre-Frontal Cortex (PFC) ve Posterior Parietal Cortex (PPC), incelenmiştir $[5,6]$. Özellikle PFC üzerinde görülmekte olan teta band1, mental işyükü arttığı durumlarda artarak pozitif korelasyon sergilemektedir [7,8]. Alfa band, özellikle PPC üzerinde gözlenmekte ve ters korelasyon sergilemektedir $[9,10,11,12,13]$. Sadece birkaç çalışma, diğer EEG bantları olan delta, beta ve gamma bandını raporlamıştır. Onton ve diğ. (2005) [14], frontal orta teta bandının hafiza yüklenmesi ile arttığını belirtirken literatürdeki önceki sonuçlarla örtüşür biçimde, frontal teta EEG aktivitesinin ve mental işyükü ile korelasyonunu onaylayan bulgular raporlamıştır [8, 11]. Zihinsel işyükünün aynı zamanda EEG alfa bandını baskıladığı ve teta bandını arttırdığı bilinmektedir [15-19]. Çoklu görev performansına dayalı bir başka çalışmada, öğrenme ile görev talebi arasındaki etkileşim psikofizyolojik reaksiyon açısından, EEG, kardiyak aktivite ve solunum sayısı kullanılarak incelenmiştir [20]. Görev talebine yanıtın parasempatik inhibisyonda azalma ve göz kırpma süresinde azalma ile karakterize olduğunu göstermişlerdir. Böylece, vagal tonun azaldığı ve kalp atım hızının (heart rate, HR) arttığı belirtilmiştir. Bu fizyolojik yanıt ile çoklu görev için gerekli odaklı konsantrasyonun karşılandığı öngörülmüştür. Bir başka deneysel çalışmada, 10 pilottan 90 dakikalık uçuş yapmaları istenen bir senaryo düzenlenerek işyükünün psikofizyolojik dayanağı incelenmiştir [21]. Kalp ritmi ölçümleri, elektrodermal ve elektriksel beyin aktiviteleri ölçümleri yapılmış ve uçuş ihtiyaçlarına göre değişimler sergiledikleri ve yüksek korelasyon gösterdikleri raporlanmıştır [21].

Kalp atım hızı (Heart Rate, HR) bilgisi, pek çok zihinsel işyükü çalışmalarında güvenilir bir ölçüt ve işyükü ile doğrudan ilintili olarak sunulmuştur [22-27]. Çalışmamızda gözlemlenen parametrelerden biri olan kalp atım hızı değişkenliği (HRV) otonom sinir sistemi ile etkileşimde olduğu için duygusal değişime bağlı olarak meydana gelen tepkilerin elektrofizyolojik ölçümlerinde rahatlıkla değerlendirilebilmektedir. HRV akut strese de duyarlıdır ve zihinsel baskılama yapıldığı zaman azaldığı gözlenmektedir. $\mathrm{Bu}$ şekilde, frekans analizleri sonucunda kalp atım hızı değişkenliği üzerinde sempatik ve parasempatik sinir sisteminin etkisi incelenebilmektedir. Frekans aralıkları yüksek, düşük ve çok düşük olmak üzere, 0.15-0.4 Hz arası ise yüksek frekans, $0.04 \mathrm{~Hz}$ değerinin aşağısı çok düşük frekans ve 0.04-0.15 Hz arası düşük frekans olarak tanımlanmaktadır [28]. Fonksiyonel MR görüntülemesi metodu ile yürütülen çalışmalar, yine mental aktivite ile beyin ağlarının dinlenim durumu ile ilişkili olduğunu göstermektedir. Benzer şekilde, dinlenim durumu beyin ağlarının Precuneus-Posterior Cingulate korteks bölgelerinin deaktivasyonu ve Anterior Cingulate korteks bölgesinin aktivasyonunun elektrodermal aktivite (deri direnci seviyesi, EDA) ile anlamlı seviyede ilintili bulunduğu raporlanmıştır [29]. 
Alfa baskılanması ve nöral yetkinlik hipotezinin strese ve zihinsel yüklenmeye bağlı olma durumu esas alınarak, çalışmamızda deneklerde fiziksel yorgunluk oluşturulmaya çalışılarak, stres yaratılması hedeflenmiştir. Strese bağlı olarak sempatik sinir sistemi aktifleşmekte ve bu durum periferde ekrin ter bezlerini uyarmaktadır. Oluşan bu uyarının ölçülmesi ise EDA yanıtını ifade etmektedir. Stresin ve yorgunluğun olduğu durumlarda beynin elektriksel aktivitesinde senkronizasyon bozukluğu oluşmakta ve bu durumda beta frekansının baskın olduğu bilinmektedir. Stresin etkin olmadığ 1 durumlarda nöral yetkinlik hipotezine uygun biçimde EEG üzerinde alfa frekansı baskın olduğu bilinmektedir [16,19].

Beynin, merkezi sinir sistemi ve otonom sinir sistemi yanıtları stres altında farklılıklar sergilemektedir. Çalışmamızda, dinlenim durumu ve mental performans esnasında beklenen bu farklılıkların, eğitimli/deneyimli ve eğitimsiz/deneyimsiz fizyoloji (sporcu ve sedanter) olmak üzere bağımsız iki gönüllü ölçüm grubu üzerinden analizi ve değerlendirilmesi amaçlanmıştır. Zihinsel aritmetik görevi ile yaratılan zihinsel işyükü esnasında elektrofizyolojik ölçümlemeler yapılmış aynı zamanda fizyolojik aktivite ile kontrollü yorgunluk ile stres yaratılarak, fiziksel performansın etkisi altındaki ölçümler ile dinlenim durumu ölçümleri karşılaştırmalı incelenmiştir. Oluşturulan deney paradigması ile farklı nitelikteki sporcu grupları üzerinde, aynı zamanda mental işyükü performansı sergilendiği durumda elektrofizyolojik değişimlerin gözlenmesi amaçlanmıştır. Aynı zamanda, görev talebini karşılama başarıları ve karar verme mekanizmalarının (görevin başarıyla yürütülmesi) durumları raporlanmış ve bulguları ile değerlendirilmiştir. Dinlenim durumunda ve fiziksel aktivite sonrasında mental işyüküne bağlı olarak EEG alfa bandı, kalp atış hızı, fotopletismografi (PPG) ve EDA ölçümlerinde oluşan değişkenlikler incelenmiştir. Dinlenim durumunda ve zihinsel aritmetik ile uyarılan beyin elektriksel aktivitesi devinimlerinde, uyanıklık (arousal) durumu alfa frekansı gücü ile tanımlanmış ve incelenmiş, otonom sinir sistemi göstergesi olaraksa HRV ölçülmüştür. Çalışmanın bir diğer amacı, eğitimli (elit) anatomi ve fizyolojilerde oksijenlenme ile ilintili biçimde, performans ardından elektrofizyolojik yanıtların elit olmayan normal gruba göre ayrışma veya benzerliğinin nicel olarak irdelenmesi olmuştur.

\section{YÖNTEM}

\subsection{Oksijen Tüketiminin Belirlenmesi}

Çalışmamıza gönüllü olarak katılan bireylerde, kontrollü fiziksel yorgunluk oluşturulabilmesi için, aerobik kapasitenin ölçülmesinde literatürde standart olan ve en yaygın olarak kullanılan, doğrudan olmayan ölçüm saha testlerinden mekik koşu (shuttle run) testi tercih edilmiştir [30]. Mekik koşusu testi, istatistiksel anlamlılık için seçilmektedir, ayrıca kolay uygulanabilirliği ve kontrol edilebilirliği açısından oldukça fazla kullanılmaktadır [31]. 20. Mekik testi, bip testi (beep test), çok seviyeli fitness testi
(Multi Stage Fitness Test) olarak da anılan testte, bireyin oksijen tüketiminin maksimum değeri (VO2max) dolaylı olarak saptanmaktır. Görev, metronom yardımıyla belirlenen sürelerde, $20 \mathrm{~m}$. uzunluğundaki koşu aralığını koşmaktır. Koşu süresi ve belirli değerler bir akıllı telefon uygulaması (BH Test) ile takip edilmektedir (Şekil 1). İlk turda, 20m.lik parkuru betimleyen iki sinyal arası 9 sn iken, ilerleyen evrelerde 3.892 sn'e kadar inerek uygulayıcının hızlanmasını sağlamaktadır. $\mathrm{Bu}$ ölçüt ile başlangıçta denek hızı 8.5 $\mathrm{km} /$ saat iken, kademeli olarak dakika başına $0.5 \mathrm{~km} / \mathrm{saat}$ artırılmaktadır. Mekik koşu testi sırasında, iki sefer zaman uyarısını kaçıran/geciktiren deneklerden testi sonlandırması istenir. Katılımcılar, parkurun tamamlanması için verilen sürenin uygulama tarafından belirlendiği şekilde kısalmasıyla hızlanarak koşmaktadırlar, maksimum fiziksel yorgunluğa ulaştıkları zaman ise koşu sonlandırılmaktadır. Toplam koşu bilgisi, literatürde belirlenmiş tablolara dayanarak [30,31], program ile otomatik hesaplanmakta ve kişinin en yüksek VO2 değeri yaklaşık olarak belirlenmektedir (Şekil 1).

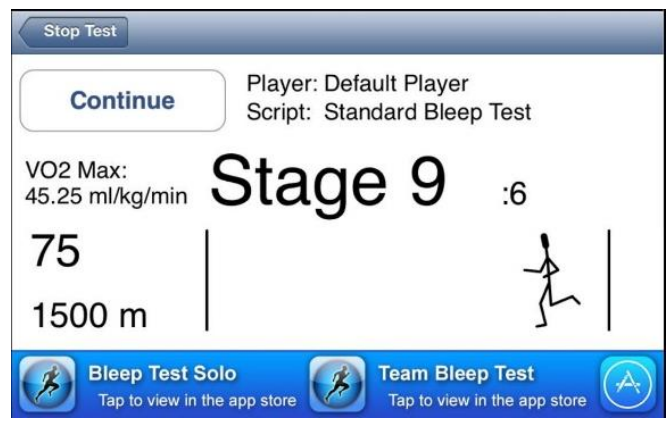

Şekil 1. Elit sporculara ait örnek mekik testi arayüzü

\subsection{Elektrofizyolojik Verilerin Toplanması}

Çalışmada, ölçüm gruplarından öncül dinlenim durumu alınarak, fiziksel aktivite sonrasında oluşan elektrofizyolojik değişimlerin (kalp atım hızı, EDA yanıtı, PPG ve EEG alfa bandı değişimi) mental aktivite ile olan bağlantısının incelenmesi amaçlanmıştır.

Dinlenim durumu ölçümleri, pilot araştırmalarımızın devam çalışması olarak tamamı göz kapalı süreçte üç faza ayrılarak gerçekleştirilmiştir. Göz kapalı (GK) ve mental aktivite (MA) olmak üzere 90 saniyelik birinci faz olan göz kapalı dinlenim durumu (GK1), ikinci faz olarak 3 dakika boyunca yine göz kapalı durumdayken verilen dört basamaklı sayıdan yedişer geri sayma görevi ile MA fazı, son faz olarak da zihinsel işlem sonlandırılarak GK dinlenim periyodu (GK2) 90 saniye için uygulanmıştır. Dinlenim durumu ardından gönüllü katılımcıların kontrollü yorgunluk amacıyla $20 \mathrm{~m}$. mekik koşu testi ile maksimum oksijenlenme miktarlarının \%80' i tespit edilerek, her bir katılımcının kendi ölçütlerinde eşit oranda yorulması sağlanmıştır. Bir başka deyişle, her katılımcı kendine ait bireysel performansın \%80 değerine ulaştığında 20m. mekik koşu testi sonlandırılmıştır (Şekil 1). 
Deneklere üç dakika dinlenme süresi verilmesinin ardından dinlenim durumunda uygulanan elektrofizyolojik ölçümleme prosedürü aynı şekilde tekrar uygulanmıştır (Şekil 2). Böylelikle fiziksel yorgunluğun mental aktiviteyle bağlantılı olarak EEG, kalp atım hızı, EDA ve PPG'de yol açtığı değişimlerin gözlemlenmesi sağlanmıştır.

Elektrofizyolojik ölçümler BIOPAC MP36 cihazı ile gerçekleştirilmiştir (Şekil 2). Sözkonusu ölçümler, elektrokardiyogram (EKG), PPG, elektrodermal aktivite (EDA) ve EEG'den oluşmaktadır ve örnekleme frekansı $2 \mathrm{kHz}$ olarak uygulanmıştır. EEG kaydı literatüre uygun şekilde $\mathrm{Ag} / \mathrm{AgCl}$ elektrotu ile alınmıştır [6,32,33]. EKG, EDA ve EEG ölçümlemeleri için kullanılan bant geçiren süzgeçler sırasıyla $0,01-35 \mathrm{~Hz}, 0$ - $35 \mathrm{~Hz}$ ve $0,5-35 \mathrm{~Hz}$ 'tir. PPG frekans bant genişliği ise 0,5-4.0 Hz'tir.

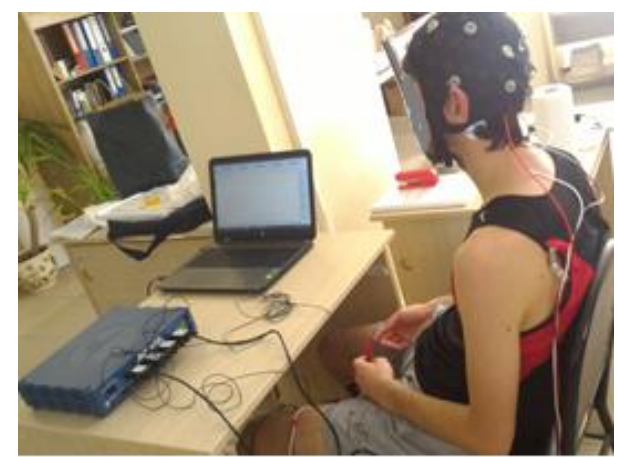

Şekil 2. Elit sporcu, örnek ölçüm.

\subsection{Elektrofizyolojik Verilerin İşlenmesi}

Süregiden EEG verisi durağan olarak kabul edilen birer saniyelik uzunlukla dilimlenmiştir. Dilimlenen zaman serilerinin ayrı ayrı güç izgeleri (1) MATLAB ortamında hesaplanmıştır. İlaveten frekans çıktıları ortalanmıştır. 2 numaralı denklem kullanılarak beyin elektriksel aktivitesi alfa bandı gücü (8-13 Hz), tüm frekans gücü $F_{n}(p)$ üzerinden normalize edilmiştir.

$$
\begin{aligned}
& F(x)=\frac{1}{N} \sum_{j=0}^{N-1} x_{k} e^{-2 \pi j k / N}, x=0, \ldots, 35 . \\
& F_{n}(\alpha)=\frac{F(\alpha)}{F(p)}, \alpha=8, \ldots, 12 .
\end{aligned}
$$

Gerçekleştirilen ölçümlerde, PPG örnekleme hızı 1kHz'tir. Tüm ölçüm gruplarındaki deneklerin verilerinde, dinlenim durumunda kaydedilen PPG sinyalleri ile, fiziksel aktivite sonrası alınan PPG sinyalleri genlik ve frekans farkı açısından niceliksel olarak grup içi ve gruplararası karşılaştırılmıştır. Araştırmamızda, fiziksel yorgunluk koşulu ön plana alınmış olup, mekik koşu testi ile sağlanan bu kontrollü yorgunluk ardından kayıtlanan PPG sinyalleri incelenmiş ve FFT genlik değişimleri analiz edilmiştir. Sporcular ile sedanter (normal) gruptaki gönüllülerin ölçüm değerleri FFT değişimleri üzerinden ve frekans farklılığı üzerinden incelenmiştir. Doğası gereği gürültülü olan PPG sinyalleri (Şekil 4), bu gürültüden temizlenerek analiz edilmiştir (Şekil 5), bu şekilde kontrollü yorgunluğa karşı tepki yanıtları daha iyi anlaşılmaktadır.
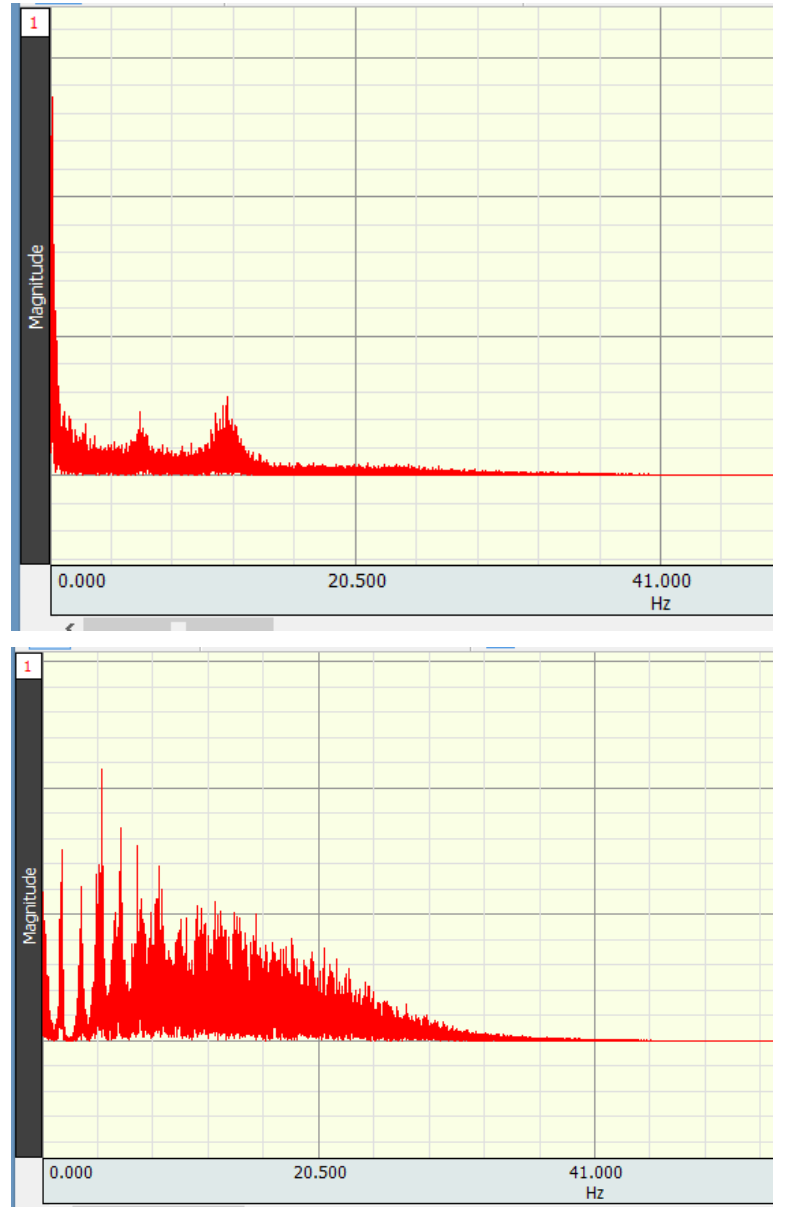

Şekil 4. PPG sinyallerinin FFT analizi: Üstte sporcu ve altta sedanter grupların test ardından kayıtlanan PPG sinyallerinin $(\mathrm{mV})$ FFT analizi görülmektedir.

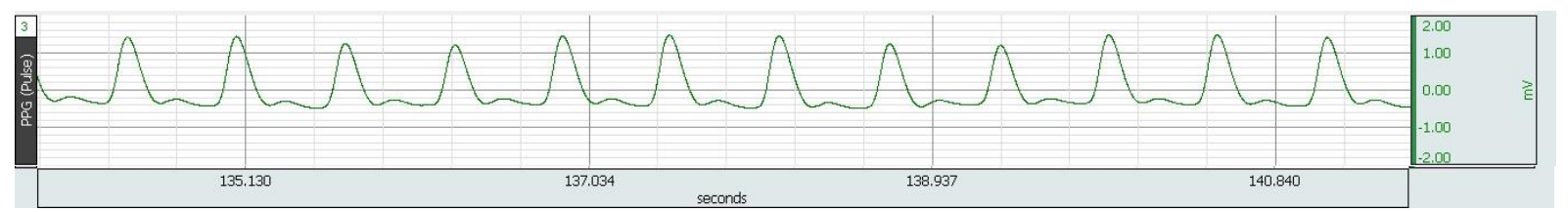

Şekil 3. PPG sinyali örneği (yatay eksen saniye biriminden zamanı temsil etmektedir, düşey eksen ise $\mathrm{mV}$ cinsinden genliği göstermektedir). 


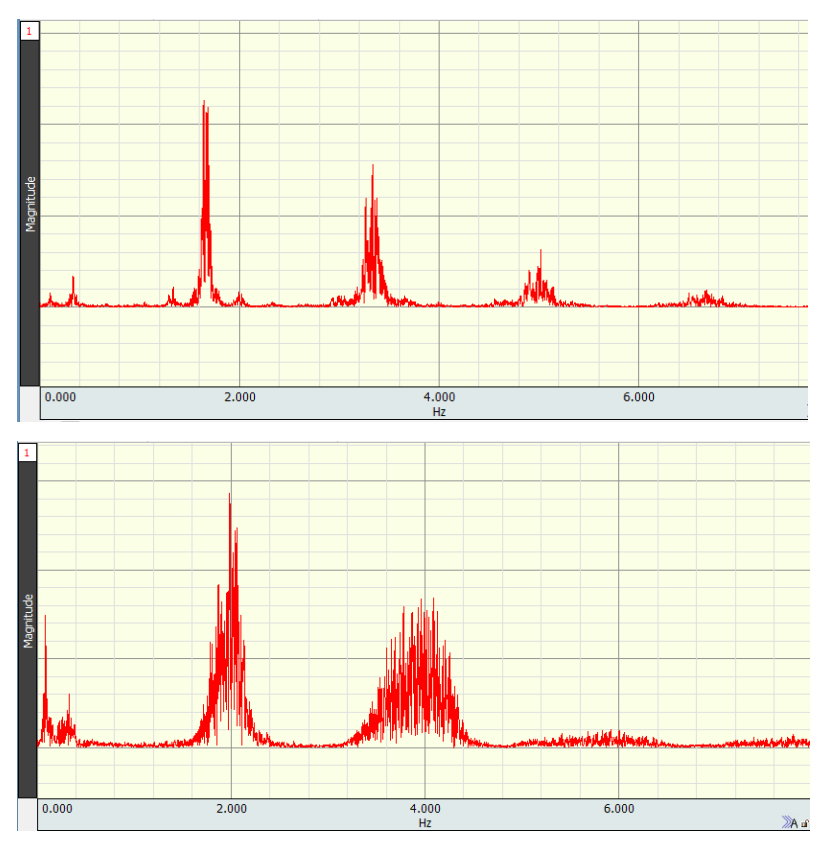

Şekil 5. Güç izgesi: Üstte sporcu, altta sedanter grup olmak üzere test ardından ölçümlenen PPG sinyallerinin frekans spektrumu görülmektedir.

PPG ölçümü ile kişinin durumuna dair bilgi sağlanabilmektedir. Bunun nedeni, PPG sinyalinin solunum veya hareket gibi bireyin sergilediği performanstan, çevresel faktörlerden etkilenmesidir.

PPG verisinden elde edilebilen değerler arasında, solunum frekansının $0.04 \mathrm{~Hz}$ ile $1.6 \mathrm{~Hz}$ arasında değiştiği, kişi bazlı hareket artefaktlarının frekans aralığının $0.1 \mathrm{~Hz}$ olması gibi ayrımlar ve periferal oksijen doyumu (SpO2), anestezi durumu, nabız gibi bilgiler yer almaktadır [34, 35, 36]. Gürültü ayrıştırması amaciyla PPG sinyallerine FIR sonlu darbe yanttl alçak geçiren (Finite Impulse Response) filtreleme (3) uygulanmıştır (Şekil 5).

$$
y_{k}=\sum_{m=0}^{M-1} h_{m} x_{k-m}
$$

FIR alçak geçiren filtre evrişim teoremi temellidir (1) ve tepki yanıtı giriş sinyalinin katlarının toplanması ile ortaya çıkmaktadır. Burada $h_{m}$ katsayısı filtrenin karakteristiğini yansitır ve filtrenin frekans özelliklerinin ters Fourier dönüşümü şeklinde saptanmaktadır [37]. Teoride M, sonsuz değerde atanmış olup, $h_{m}$ pozitif ve negatif indis değerleri olarak öngörülmektedir. Filtrenin tepki yanıtı, ölçümlenen $x$ için $k$ zamanında, geçmiş $\left(x_{k-1}, x_{k-2}, \ldots, x_{k-m}\right)$ ve gelecek $\left(x_{k+1}\right.$, $\left.x_{k+2}, \ldots, x_{k+\mathrm{m}}\right)$ zaman şeklinde bulunmaktadır [37]. Çalışmamızda, verilen tepki sinyaline sonlu yanıt alınabileceğinden ötürü, incelenen grupların ölçüm yanıtlarının değerlendirilmesinde FIR alçak geçiren filtre ile çalışılmıştır.

\section{4. İstatistiksel Analiz}

Onaltı kişininin iki farklı oturumda, EEG, EKG, EDA ve PPG ölçümleri gerçekleştirilmiştir. Her oturumda, mental işyükü ve dinlenim durumuna dair alınan ölçümlerin farkı alınarak iki grup arasında non-parametrik Mann Whitney U testi kullanılarak karşılaştırılmıştır. EEG sinyalinin alfa bandı baskılanması (delta, $\Delta$,), EKG'nin farklı frekanslarına (yüksek, düşük ve çok düşük olmak üzere, $0.15-0.4 \mathrm{~Hz}$ arası ise yüksek frekans, $0.04-0.15 \mathrm{~Hz}$ arası düşük frekans ve $0.04 \mathrm{~Hz}$ değerinin aşağısı çok düşük frekans olarak) tekabül eden güçlerinin dinlenim ve mental işyükü arasındaki farkları, EDA sinyalinin tonik ve fazik bileşenlerinin dinlenim ve mental işyükü arasındaki farkları ve PPG nin dinlenim ve mental işyükü arasındaki genlik farkı istatistiksel karşılaştırmaya ayrı ayrı konu edilmiştir. İstatistiksel anlamlılık seviyesi 0.05 olarak kabul edilmiştir.

\subsection{Katılımcılar ve Etik Beyan}

Nöral yetkinlik hipotezinin incelenmesi amacıyla sporcular ve sedanter katılımcılar gönüllü olarak çalışmamıza katkı sağlamışlardır. Ulusal ve uluslararası başarıları olan milli sporcular ve amatör ligde sportif faaliyet yürüten katılımcılar sporcu grubu ve hiçbir sportif faaliyette bulunmayan gönüllüler sedanter grubu oluşturmuştur.

Araştırmaya katkıda bulunan gönüllü grup, eğitim seviyeleri eşdüzey, yaş ve cinsiyet açısından da eş kriterler barındıran (20-30 yaş, erkek), herhangi bir nörolojik rahatsızlık geçmişi bulunmayan ve ilaç kullanmayan 16 kişiden oluşmaktadır.

Bu çalışma İstanbul Arel Üniversitesi Etik Kurulu 2016/06 numaralı ve 23.12.2016 tarihli onayı ile, ve Helsinki Deklerasyonu prensiplerine uygun şekilde yürütülmüştür.

\section{BULGULAR}

Mekik koşusu testi ile öncelikle deneklere ait maksimum fiziksel performans değerleri belirlenmiştir. Gönüllü sporculardan oluşan deneklere ait örnek değer tablosu Tablo 1 'de belirtilmiştir.

EEG ölçümünden gelen zaman serilerinin birer saniyelik pencerelerde epoklanması ile güç izgesi elde edilmiş ve frekans çıktıları ortalanarak hesaplanmıştır. EEG'nin 8-13 $\mathrm{Hz}$ arasındaki alfa frekansı incelenerek gücü normalize edilmiş ve tüm frekans gücüne ulaşılmıştır.

Ortalama EEG frekans spektrumu Şekil 6'da görülebilmektedir. $\mathrm{Bu}$ spektrumda, mavi renk göz kapalı dinlenim durumunu, yeşil renk ise mental aritmetik faza ait ortalama EEG frekans dağılımını göstermektedir. Tüm gruplara ait dinlenim durumları sol sütunda, mental aritmetik paradigmasına ait tüm grupların frekans spektrumu ise sağ sütunda verilmiştir.

Şekil 6 ve Şekil 7'de gözlemlendiği üzere, literatürle örtüşür şekilde elit sporcularda diğer denek gruplarına göre EEG alfa baskılanması daha belirgin olduğu görülmektedir. 
Tablo 1. Katılımcıların mekik koşusu performans değerleri

\begin{tabular}{|l|c|c|c|c|c|c|c|c|c|}
\hline & & \multicolumn{4}{|c|}{ Maksimum değerler } & \multicolumn{3}{c|}{ Maksimum değerlerin \%80 değerleri } \\
\hline & Yaş & VO2max & Stage & Mesafe $(m)$ & Nabız & \%80 VO2 & Stage & Mesafe $(m)$ & Nabız \\
\hline Denek1 & 23 & 31.76 & 5 & 740 & 180 & 25.408 & 3 & 440 & 162 \\
\hline Denek2 & 20 & 36.76 & 7 & 1000 & 192 & 29.408 & 5 & 620 & 156 \\
\hline Denek3 & 22 & 46.20 & 9 & 1560 & 198 & 36.96 & 7 & 1000 & 174 \\
\hline Denek4 & 22 & 28.30 & 4 & 560 & 186 & 22.64 & 3 & 300 & 162 \\
\hline Denek5 & 21 & 31.01 & 5 & 700 & 162 & 24.81 & 3 & 420 & 132 \\
\hline Denek6 & 21 & 46.20 & 9 & 1560 & 180 & 36.96 & 7 & 1000 & 160 \\
\hline Denek7 & 23 & 44.29 & 9 & 1660 & 170 & 35.432 & 7 & 1020 & 160 \\
\hline Denek8 & 20 & 52.02 & 11 & 2120 & 162 & 41.616 & 8 & 1440 & 146 \\
\hline Denek9 & 20 & 54.29 & 12 & 2360 & 162 & 43.432 & 9 & 1660 & 150 \\
\hline Denek10 & 23 & 38.14 & 7 & 1060 & 198 & 30.512 & 5 & 1000 & 160 \\
\hline Denek11 & 20 & 38.48 & 7 & 1100 & 180 & 30.784 & 5 & 1020 & 164 \\
\hline Denek12 & 22 & 57.10 & 12 & 2600 & 130 & 45.68 & 10 & 2120 & 120 \\
\hline Denek13 & 24 & 58.80 & 13 & 2740 & 112 & 47.04 & 11 & 2240 & 110 \\
\hline Denek14 & 23 & 42.34 & 8 & 1340 & 192 & 33.872 & 6 & 860 & 178 \\
\hline Denek15 & 23 & 43.60 & 9 & 1680 & 190 & 34.88 & 6 & 920 & 162 \\
\hline Denek16 & 22 & 40.87 & 8 & 1240 & 192 & 34.40 & 6 & 880 & 170 \\
\hline
\end{tabular}

Alfa baskılanması, her grup adına, dinlenim durumunda ve fiziksel aktivite sonrası gerçekleştirilen zihinsel işyükü (mental aritmetik işlemi) esnasında elektrofizyolojik ölçümleme süresince, GK1, MA, GK2 fazlarında takip edilmiştir. MA akabinde hem sporcu hem sedanter grup verilerinde alfa düşüşü saptanmıştır. Değişim, her grup için kendi dinlenim durumu ve fiziksel yorgunluk sonrası ölçümlenen EEG verisindeki alfa bandı zaman pencereleri ve MA, GK2 geçiş süreci incelenerek saptanmıştır. Nicel olarak, tepe noktasının ani düşüş sergilediği (deney paradigmasında işyükü faz geçiş) kısımları saptanarak, varyasyonuna bakılmıştır (4).

$$
\Delta_{i}=F_{n_{\text {dinlenim }}}(\alpha)-F_{n_{\text {mekik }}}(\alpha)
$$

Delta, $\Delta$, ile temsil edilen parametre, alfa baskılanmasını nicel olarak ifade eden, $i$ 'nin sporcu ve normal (sedanter) grup olarak iki farklı durumu için, n'nin EEG frekans spektrumunda dinlenim durumu tepe noktası ve mekik koşu sonrası ölçümde elde edilen tepe noktasının varyasyonu olarak hesaplanmıştır (4).

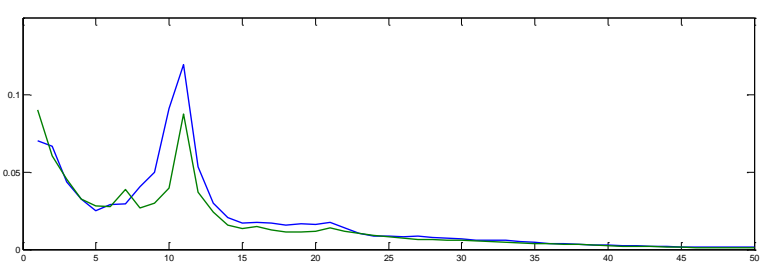

a) Sedanter dinlenim

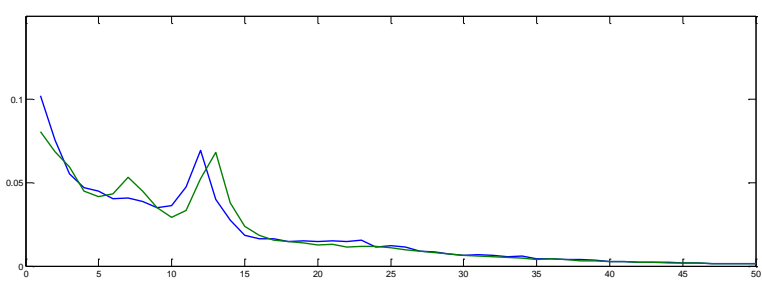

c) Sporcu dinlenim

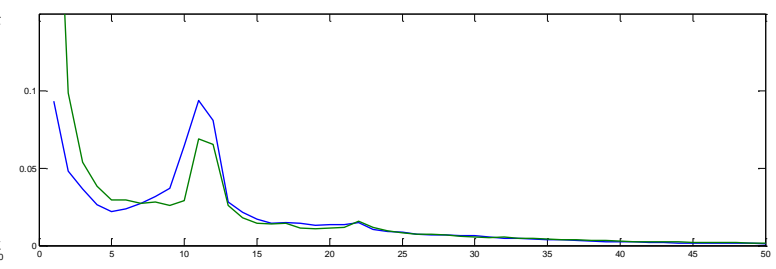

b) Sedanter mekik

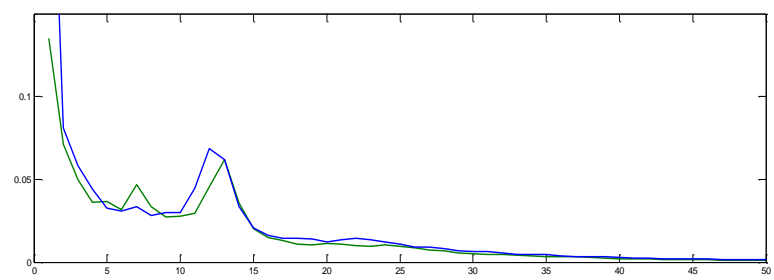

ç) Sporcu mekik

Şekil 6. Deneklerin dinlenim durumu ve fiziksel performans sonrası elektrofizyolojik ölçümleri: Ortalama EEG frekans spektrumu: (mekik testi öncesinde) a) Sedanter, c) Sporcu frekans spektrumunu, (mekik testi sonrası) b) Sedanter, ç) Sporcu frekans spektrumunu göstermektedir. 


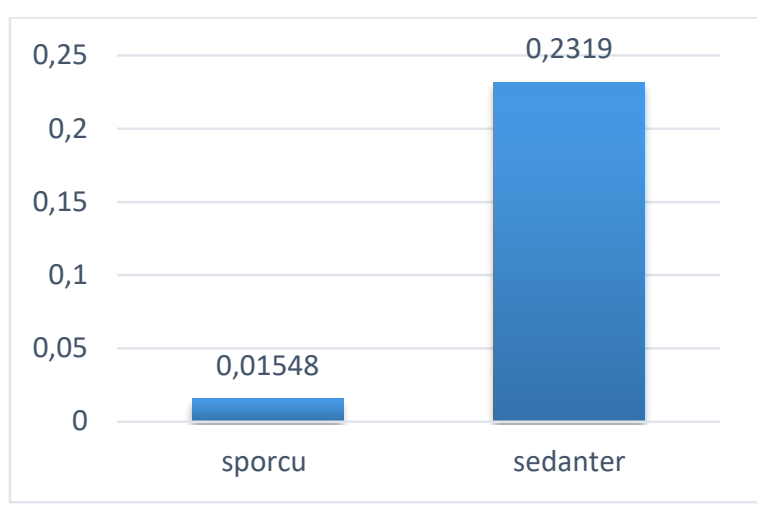

Şekil 7. Gruplararası EEG alfa baskılanması dağılımı

Katılımcı gruplarının EEG frekans spektrumları incelendiğinde, EEG alfa bandı baskılanması değişiminin en düşük değerine sporcu grubunda rastlanmış olup $\left(\Delta_{\mathrm{s}}=0.01548\right)$, sirasiyla sedanter $\left(\Delta_{\mathrm{n}}=0.2319\right)$ grupların EEG alfa baskılanma değişim değerleri daha belirgin olarak gözlenmiştir (Şekil 7). Bu bulgular nöral yetkinlik hipotezini desteklemektedir. Elit sporcuların performansa dayalı fiziksel yorgunluk ve zihinsel işyükü aktivitesi sırasında, eğitimli fizyolojiye sahip olan grup olarak, duruma alışık oldukları ve fizyolojik olarak öğrenilmişlik sözkonusu olduğu için daha az beyin aktivitesi ile doğru karara ulaştıkları, atanmış görevi rahatlıkla yerine getirdikleri saptanmış ve bu bulguların elektrofizyolojik kanıtı elde edilmiştir. Kalp atım hızı değişkenliği, sedanter grup ve sporcu grup için hesaplanarak yüksek, düşük ve çok düşük frekansta spektral dağılımında tespit edildiği gibi, parametrik olmayan istatistik test uygulanarak elit sporcu kalp atım hızı değişkenliğinin $0.15-0.4 \mathrm{~Hz}$ arası etkin yüksek frekans GK dinlenim koşulu için istatistiksel anlamlı olduğunu gözlenmiştir $(\mathrm{p}=0.04)$. Burada grupların benzeşmesi başlangıç hipotezi farz edilmiş, alternatif hipotez olaraksa istatistiksel anlamlı farklılaşması kabulüne dayanılmıştır. Sporcular ile sedanterler karşılaştırıldığında, sporcu grupta EEG'de alfa baskılanmasının daha belirgin olduğu gözlenmiştir. Zihinsel performans (MA) sırasında alfa aktivitesi diğer durumlardakinden (GK1 ve GK2) düşük saptanmıştır (Şekil 6). Bu durum, zihinsel aktivite esnasında alfa baskılanmasının göstergesidir (Şekil 7).

Deri iletkenliğine bakıldığında ise, EDA'nın zihinsel işyükü ve dinlenim durumları arasında tonik ve fazik bileşenlerde farklılaştığı, zihinsel efor sırasında tonik bileşeninin ortalamasında artış olduğu gözlenmiştir. Yine analizler sonucunda, sporcu grup PPG yanitlarının sedanter gruptaki gönüllülere oranla daha az ve kısa genlikli oldukları saptanmıştır (Şekil 4-5). Bunun dayanağı olarak, özel grup seçilen sporcu katılımcıların, sportif altyapıları daha güçlü ve yetkin olması öngörülmektedir. Karşılaştırmalı incelendiğinde, iki örnek arasındaki PPG'de, mekik seviyeleri yüksek olan sporcu katılımcıların nabız değerlerinin dakikada 110 ile 130 atım aralığında varyasyon gösterirken, karşılaştırmalı normal gruptaki deneklerin nabızları dakikada 180 ile 200 atım aralığında seyretmektedir. Kalp atım verileri göz önüne alınarak değerlendirildiğinde, sporcu gönüllülerin fiziksel egzersize toleransları daha fazla olduğundan, literatür ile uyumlu biçimde sedanter katılımcıların nabız değerleri sporculara göre daha yüksek saptanmıştır.

\section{TARTIŞMA}

$\mathrm{Bu}$ çalışmada, fiziksel yorgunluk ve mental işyükünün sporcular ve sedanterler olarak iki farklı grup için elektrofizyolojik ölçümlerinin etkisi araştırılmıştır. Parametrik olmayan istatistik test bulguları göz kapalı dinlenim durumuna ait yüksek frekans aralığında istatistiksel anlamlılık gösterirken, düşük frekans ve çok düşük frekans aralıkları için anlamlı fark sunmamaktadır. Mental aritmetik paradigması ile oluşturulan zihinsel işyükünün, literatürde tanımlı kontrollü performans tatbiki ile kontrollü fiziksel yorgunluk oluşturulan gönüllülerde de EEG alfa düşüşü yarattığı ve sporcu gönüllülerde alfa baskılanmasının kendi içinde daha az olduğu gözlemlenmiştir. Elde edilen bu öncül bulgular doğrultusunda sporcu grup için, sedanter gruba kıyasla odaklanmalarının daha başarılı olduğu ve fiziksel yorgunluk etkisine rağmen zihinsel işyükünden daha az etkilendikleri öngörülebilir. Nöral yetkinlik hipotezine göre, bilişsel testlerde, görece düşük beyin aktivitesinin daha yeterli ve yetkin anlamında olduğu, az enerji ve düşük beyin aktivitesi ile aynı bilişsel işlevin yerine getirilebildiği belirtilmektedir [2,3]. Dolayısıyla konusunda eğitimli bireylerin öğrenme ile beyin aktivitelerini efektif kullandığ ve profesyoneller ile amatörler arasinda karar verme mekanizmasının farklılığı söylenebilmektedir [4]. Sözkonusu bilişsel görevlerin zorluk seviyesinin kolaydan zora değişim göstermesi nöral yetkinlik hipotezini değiştirmemektedir. Her seviyedeki bilişsel görev için daha zeki bireylerin daha efektif beyin aktivitesi sergilediği belirtilmekte ve çalışmamızda bulgularda belirtildiği ve hipotezle örtüştüğü gibi baskılanmış, değişimi düşük beyin aktivitesi sergilediği görülmektedir. Aritmetik mental geri sayma görevinin başarı ile sürdürülmesi ve deney ardından boy, yaş, kilo gibi basit sorular karşısında sergilenen performans değerlendirildiğinde, elitlerin başarı yüzdesinin $\% 50$ oranında yüksek olduğu saptanmış, sedanterlerin mental efora bağlı olarak performans düşüşü yaşadığı gözlenmiştir.

İki grup katılımcıya yönelik elektrofizyolojik ölçüm sonuçları incelendiğinde, nöral yetkinlik hipotezinde öngörüldüğü şekilde sporcuların daha yetkin oldukları ve düşük beyin aktivitesi ile aynı bilişsel fonksiyonu gerçekleştirdikleri saptanmıştır. VO2max ölçümü, oksijen tüketim hızının en yüksek değerini bildirirken, kardiyorespiratuvar dayanıklılık ölçütü aerobik kapasitenin ölçümünü sağlamıştır. Mental işyükü ile bağlantılı olan kalp atım hızı değişkenliği ve eşzamanlı EEG ölçümleri, literatürde yer alan nöral yetkinlik hipotezi ile örtüşmektedir.

Değişen zorluk seviyelerinde mental aritmetik ve zihinsel işyükü görevleri uygulanarak kişilerin beyin karakteristiğini yansıtan örüntüler elde edilebilir. Çalışmamızdaki amaç, eğitimli fizyolojiye sahip, ayrıca en yüksek oksijen 
tüketiminin (VO2max) ölçütü olarak aerobik kapasitesi gelişmiş kişilerin, kontrollü ve mukayeseli fiziksel performans ve yorgunluk durumunda karar verme mekanizmalarının, dolayısıyla EEG alfa odaklanma aktivitelerinin ve değişimlerinin araştırılması olmuştur.

Son yıllarda, zihinsel işyükü ve elektrofizyolojik ölçümleme arasındaki ilişki sıklıkla araştırılmaktadır. Bu çalışmanın amacı, artan zihinsel işyükü ile otonomik ve merkezi sinir sisteminin elektrofizyolokij yanıtlarının ölçümlenmesi ve değerlendirilmesidir.

EEG, PPG, EDA, EKG ölçümlerinin farklı kombinasyonlarının birlikte gerçekleştirildiği çalışmalara literatürde sıklıkla rastlanmaktadır. Bu ölçümlerin tümünün eşzamanlı olarak sporcu grup üzerinde mental işyükü parametresi özelinde gerçekleştirildiği çalışmamız, literatürde özgün bir yere sahiptir. Bulgularımız gelecek çalışmalar için temel oluşturmaktadır.

\section{TEŞEKKÜR}

Araştırmamıza katkı sağlayan gönüllü katılımcılarımız, Marmara Üniversitesi Spor Bilimleri Fakültesi öğrencileri Milli Sporcularımıza, İstanbul Arel Üniversitesi Bilgisayar Mühendisliği, Biyomedikal Mühendisliği ve ElektrikElektronik Mühendisliği öğrencilerine destekleri ve katılımları için teşekkür ederiz.

\section{KAYNAKÇA}

[1].P.A. Hancock, J.S. Warm, “A Dynamic Model of Stress and Sustained Attention." Human Factors and Ergonomics Society 31, 519-537, 1989.

[2].B. Dunst, M. Benedek, E. Jauk, S. Bergner, K. Koschutnig, M. Sommer, A. Ischebeck, B. Spinath, M. Arendasy, M., Bühner, H. Freudenthaler, A.C. Neubauer, "Neural efficiency as a function of task demands." Intelligence, 42, 22-30, 2014.

[3].A.C. Neubauer, A. Fink, "Intelligence and neural efficiency." Neurosci. Biobehav. Rev., 33(7), 1004-23, 2009.

[4].T.H. Balcığlu, D. Şahin, M. Assem, S.B. Selman, D. Göksel Duru, "Göz Hareketleri Takibi ile Elit Sporcularda Bakış Karakteristikleri Analizi: Pilot Çalışma.” 18. Ulusal Biyomedikal Mühendisliği Toplantısı Kitapçığı, s. 1-4, 2014.

[5].M. Chaouachi, I. Jraidi, C. Frasson, "Modeling Mental Workload using EEG Features for Intelligent Systems.” Intl. Conf. User Modeling, Adaptation, Personalization, p. 50-61, 2011.

[6].D.C. Lefebvre, Y. Marchanda, G.A. Eskes, J.F. Connolly, "Assessment of working memory abilities using an event-related brain potential (ERP)-compatible digit span backward task," Clinical Neurophysiology 116, 1665-1680, 2005.

[7].A. Gevins, M.E. Smith, "Neurophysiological measures of cognitive workload during human-computer interaction." Theor. Issues Ergon. Sci. 4, 113-131, 2003.
[8].A.S. Smit, P.A. Eling, M.T. Hopman, A.M. Coenen, "Mental and physical effort affect vigilance differently," Int J Psychophysiol. 57(3):211-7. Epub 2005 Apr 8, 2005.

[9].W. Klimesch, M. Doppelmayr, T. Pachinger, B. Ripper, "Brain oscillations and human memory: EEG correlates in the upper alpha and theta band. Neurosci. Lett. 238, 9-12, 1997.

[10].J.B. Brookings, G.F. Wilson, C.R. Swain, "Psychophysiological responses to changes in workload during simulated air traffic control." Biol. Psychol. 42, 361377, 1996.

[11].A. Gevins, M.E. Smith, L. McEvoy, D. Yu, "Highresolution EEG mapping of cortical activation related to working memory: effects of task difficulty, type of processing, and practice. Cereb. Cortex N. Y. N, 7, 374-385, 1997.

[12].L. Venables, S.H. Fairclough, "The influence of performance feedback on goal-setting and mental effort regulation. Motiv. Emot. 33, 63-74. doi:10.1007/s11031008-9116-y, 2009.

[13].N. Jaušovec, K. Jaušovec, "Working memory training: improving intelligence--changing brain activity." Brain Cogn. 79, 96-106, 2012.

[14].J. Onton, A. Delorme, S., Makeig, "Frontal midline EEG dynamics during working memory." NeuroImage 27, 341-356, 2005.

[15].W. Klimesch, M. Doppelmayr, T. Pachinger, B. Ripper, "Brain oscillations and human memory: EEG correlates in the upper alpha and theta band." Neurosci. Lett. 238, 9-12, 1997.

[16].W. Klimesch, M. Doppelmayr, H. Schimke, B. Ripper. "Theta Synchronization and Alpha Desynchronization in a Memory Task.” Psychophysiology, 34(2-1997), 169-76, 1997.

[17].W. Klimesch, M. Doppelmayr, H. Russegger, T. Pachinger, J. Schwaiger. "Induced alpha band power changes in the human EEG and attention." Neurosci. Lett. 244: 73-76, 1998.

[18].W. Klimesch, "EEG alpha and theta oscillations reflect cognitive and memory performance: a review and analysis." Brain Res. Brain Res. Rev. 29, 169-195, 1999.

[19].D.A. Valentino, J.E. Arruda, S.M. Gold, "Comparison of QEEG and Response Accuracy in Good vs. Poorer Performers During a Vigilance Task.” International Journal of Psychophysiology, 15, p. 123-134, 1993.

[20].S.H. Fairclough, L. Venables and A. Tattersall, "The influence of task demand and learning on the psychophysiological response." International Journal of Psychophysiology, vol. 56, n. 2, p. 171-184, 2005.

[21].G.F. Wilson, "Air-to-ground training missions: a psychophysiological workload analysis," Ergonomics, vol. 36, n. 9, p. 1071-1087, 1993.

[22].A.H. Roscoe, “Assessing pilot workload. Why measure heart rate, HRV and respiration?, "Biol Psychol, vol. 34, n. 2-3, p. 259-287, 1992.

[23].A.H. Roscoe, "Heart rate as a psychophysiological measure for in-flight workload assessment," Ergonomics, vol. 36, n. 9, p. 1055-1062, 1993. 
[24].G.F. Wilson, P. Fullenkamp and I. Davis, "Evoked potential, cardiac, blink, and respiration measures of pilot workload in air-to-ground missions," Aviat Space Environ Med, vol. 65, n. 2, p. 100-105, 1994.

[25].J.A. Veltman and A.W. Gaillard, "Physiological indices of workload in a simulated flight task," Biol Psychol, vol. 42, n. 3, p. 323-342, 1996.

[26].T.C. Hankins and G.F. Wilson, "A comparison of heart rate, eye activity, EEG and subjective measures of pilot mental workload during flight," Aviat Space Environ Med, vol. 69(4), p. 360-367, 1998.

[27].G.F. Wilson, C.R. Swain and P. Ullsperger, "EEG power changes during a multiple level memory retention task," Int J Psychophysiol, vol. 32, n. 2, p. 107-118, 1999. [28].D.L. Eckberg, "Human sinus arrhythmia as an index of vagal cardiac outflow,” J. Appl. Physiol., cilt 54, s. 961-66, 1985.

[29].S. Zhang, S. Hu, H.H. Chao, X. Luo, O.M. Farr, and C.R. Li, "Cerebral correlates of skin conductance responses in a cognitive task" Neuroimage. 62(3): 1489-1498, 2012.

[30].A. Hızal, C. Açıkada, T. Hazır, C. Tınazcı, "Modifiye Mekik Koşusu Testinin Güvenilirliği ve Geçerliği," Spor Bilimleri Dergisi Hacettepe Journal of Sport Sciences, cilt 8, say1 4, s. 3-12, 1997.
[31]. A.D. Flouris, G.S. Metsios, Y. Koutedakis. "Enhancing the efficacy of the $20 \mathrm{~m}$ multistage shuttle run test," British. J. Sports Medicine, cilt 39, s. 166-170, 2005.

[32].H. Jasper H. "Report of the Committee on Methods of Clinical Examination in Electroencephalography. Electroenceph. Clin. Neurophysiol.,10:370-375, 1958.

[33].S. Dong, L.M. Reder, Y. Yao, Y. Liu, F. Chen, "Individual differences in working memory capacity are reflected in different ERP and EEG patterns to task difficulty", Brain Res. 2015 Aug 7;1616:146-56, Epub 2015 May 11.

[34].J.J. Carr and J.M. Brown, "Introduction to Biomedical Equipment Technology", Prentice-Hall, Upper Saddle River, NJ, USA, 1998.

[35].T.L. Rusch, et al., "Signal processing methods for pulse oximetry," Comput. Biol. Med., vol. 26, no. 2, pp. 143-159, 1996.

[36].S.M.L. Silva, R. Giannetti, R., et al., "Heuristic Algorithm for Photoplethysmographic Heart Rate Tracking During Maximal Exercise Test", Journal of Medical and Biological Engineering, 32(3): 181-188, 2011.

[37].J.G. Proakis and D.K. Manolakis, "Digital Signal Processing, 4th Edition by (Publisher: Pearson; 4 edition, April 7, 2006. 